\title{
Ansiedade dos estudantes diante da expectativa do exame vestibular ${ }^{1}$
}

\author{
Adriana Benevides Soares \\ Universidade Salgado de Oliveira, UNIVERSO, Rio de Janeiro-RJ, Brasil \\ Janaína Siqueira Rodrigues Martins ${ }^{2}$ \\ Universidade Gama Filho, Rio de Janeiro-RJ, Brasil
}

\begin{abstract}
Resumo: O presente estudo investigou a ansiedade dos jovens estudantes de escolas particulares de um estado do Brasil em relação ao exame vestibular. A amostra foi composta por 124 estudantes do ensino médio participantes do vestibular seriado PISM (Processo de Ingresso Seletivo Misto), sendo 66 do gênero feminino e 58 do gênero masculino, 69 alunos do $1^{\circ}$ ano do ensino médio e 55 do $3^{\circ}$ ano. Os estudantes responderam a um questionário sócio-demográfico e ao Inventário de Ansiedade Traço-Estado (IDATE) na suas próprias salas de aula. Foi observada uma diferença significativa quanto ao gênero $(p=0,036)$ sendo que foi encontrado um maior nível de ansiedade-estado nas mulheres do $1^{\circ}$ ano comparativamente aos rapazes do $1^{\circ}$ ano $(p=0,004)$. O mesmo resultado foi encontrado com relação à ansiedade-traço: moças do $1^{\circ}$ ano são mais ansiosas do que rapazes do $1^{\circ}$ ano $(p=0,000)$.
\end{abstract}

Palavras-chave: ensino médio, estudantes, Inventário de Ansiedade Traço-Estado.

\section{The anxiety of students at the expectation of attending colleges' entrance examination}

\begin{abstract}
This study investigated the anxiety of private schools students at the expectation of attending colleges' entrance examination in one Brazilian state. The sample consisted of 124 high school students participating in the PISM series of examination (Joint Selective Admission Process). They were 66 females and 58 males, 69 students from the $1^{\text {st }}$ year and 55 from the $3^{\text {rd }}$ year. Students answered a sociodemographic questionnaire and the State-Trait Anxiety Inventory in their respective classrooms. A significant difference regarding gender $(p=0.036)$ was found, women from the $1^{\text {st }}$ year presented higher levels of state-anxiety compared to men from the $1^{\text {st }}$ year $(p=0.004)$. The same result was found with respect to the trait-anxiety, women from the $1^{\text {st }}$ year were more anxious than men from the $1^{\text {st }}$ year $(p=0.000)$.
\end{abstract}

Keywords: secondary education, students, State Trait Anxiety Inventory.

\section{La ansiedad de los estudiantes ante la expectativa del examen de ingresso a la universidad}

\begin{abstract}
Resumen: Este estudio investigó la ansiedad de los estudiantes en las escuelas privadas en un estado de Brasil en el examen de ingreso. La muestra fuese compuesta de 124 estudiantes de la escuela secundaria participantes del PISM (Proceso de Admisión Común), siendo 66 mujeres e 58 hombres, 69 alumnos del $1^{\text {er }}$ año de escuela secundaria y 55 del $3^{\text {er }}$ año. Los estudiantes respondieron a un cuestionario socio-demográfico y al Inventario de Ansiedad Rasgo-Estado (IDATE), en sus propias aulas. Hubo una diferencia significativa en relación con el género $(p=0,036)$ que se encontró un mayor nivel de ansiedad estado en el $1^{\text {er }}$ año de las mujeres en comparación con los hombres del $1^{\text {er }}$ año $(p=0,004)$. El mismo resultado se encontró con respecto a la ansiedad-rasgo: las mujeres de $1^{\text {er }}$ año son más ansiosas que los hombres del $1^{\text {er }}$ año $(p=0,000)$.
\end{abstract}

Palabras clave: educación secundaria, estudiantes, Inventario de Ansiedad Rasgo-Estado.

O vestibular é um exame que qualifica os estudantes a ingressar na universidade e, portanto, tem prerrogativas seletivas e classificatórias. A maioria dos estudantes que se submetem a este tipo de exame é de adolescentes que estão em fase final de conclusão do ensino médio.

O vestibular seriado é uma abertura possibilitada pela nova Lei de Diretrizes e Bases (LDB) da Educação Nacional. Essa Lei 9394/96 estabelece que “a Educação Superior abrange cursos e programas de graduação, abertos a

1 Esse texto foi revisado seguindo o Acordo Ortográfico da Língua Portuguesa (1990), em vigor a partir de $1^{\circ}$ de janeiro de 2009.

2 Endereço para correspondência:

Prof $^{\mathrm{a}}$ Adriana Benevides Soares. Universidade Salgado de Oliveira. Mestrado em Psicologia. Av. Rua Marechal Deodoro, 263, centro. CEP: 24.030-060. Niterói-RJ, Brasil. E-mail: adribenevides@gmail.com candidatos que tenham concluído o ensino médio ou equivalente e tenham sido classificados em processo seletivo" (LDB, Cap. IV, Art. 44). Algumas universidades, em sua autonomia didático-científica, organizaram programas alternativos de acesso ao ensino superior nomeados "vestibular seriado". Tais programas pretendem constituir-se em um meio alternativo ao vestibular tradicional.

Em meados da década de 1980, a busca por formas mais democráticas de acesso à universidade foi tema de vários fóruns de discussão organizados e promovidos pelo MEC e algumas universidades. Neste período já era discutida pela Fundação CESGRANRIO e pela Universidade de Brasília (UnB) a possibilidade de acionar mecanismos seletivos que avaliassem os alunos ao longo do curso secundário. Em 1995, a UnB reinicia os estudos sobre as alternativas ao vestibular e implanta, em 1996, o Programa de Acesso ao 
Ensino Superior (PAS). Ainda em 1995, a Universidade de Santa Maria desencadeia o Programa de Ingresso ao Ensino Superior (PEIES).

O Programa de Ingresso Seletivo Misto (PISM) é um programa de avaliação seriada, realizado anualmente, em módulos consecutivos de avaliação, gradual e cumulativa, sendo que a participação dos candidatos se dá em três módulos, um ao final de cada ano do ensino médio, caracterizandose um triênio, a saber: $1^{\circ}$ ano (ao final do $1^{\circ}$ ano) - módulo I, $2^{\circ}$ ano (ao final da $2^{\circ}$ ano) - módulo II; e $3^{\circ}$ ano (ao final do $3^{\circ}$ ano) - módulo III.

Segundo o Instituto Nacional de Estudos e Pesquisas Educacionais - INEP (2006), cerca de cinco milhões de brasileiros se inscrevem por ano no vestibular e apenas pouco mais de um milhão conquistam uma vaga nas faculdades, estes são os últimos dados consolidados da educação Superior Básica do Centro de Educação Superior. Com estas constatações nota-se que a maior parte de quem presta o exame para o vestibular não atinge seu objetivo inicial, reforçando assim o temor dos estudantes frente a tal avaliação.

Para participarem do Vestibular Seriado (PISM) os candidatos deverão se inscrever anualmente no programa a partir do $1^{\circ}$ ano do ensino médio, quando passarão a fazer parte de um grupo de candidatos de um mesmo triênio. O estudante que, estando no $2^{\circ}$ ano do ensino médio, não tenha participado do PISM no ano anterior só poderá pleitear uma das vagas oferecidas em concurso vestibular tradicional. $\mathrm{O}$ cancelamento da participação do candidato se dará a partir do momento em que for reprovado no $1^{\circ}$ ano do ensino médio, onde este poderá reinscrever-se no ano seguinte novamente no Módulo I, passando, portanto, a pertencer a um outro triênio. Ou se for reprovado nos $2^{\circ}$ ou $3^{\circ}$ ano do Ensino Médio não poderá continuar o processo e, conseqüentemente, só poderá concorrer a uma das vagas oferecidas nos cursos do Concurso Vestibular.

É difícil escolher a profissão quando ainda se vivencia crises e conflitos típicos da adolescência. O jovem não possui o auto-conhecimento necessário e nem a maturidade suficiente necessária para a escolha profissional propriamente dita (Bianchetti, 1996). Segundo D’Avila e Soares (2003), para o adolescente, o exame vestibular ou processo seletivo gera conflitos, dúvidas, medo, ansiedade e estresse. O medo da reprovação no vestibular é o principal fator para desencadear a ansiedade. Este medo está relacionado com a avaliação do seu estudo, com o enfrentamento das expectativas da família e da sociedade, com a possibilidade do fracasso, com a incerteza relativa à escolha profissional, com o excessivo número de matérias para estudar e o elevado número de candidatos por vaga (Levenfus, 1993).

Os adolescentes estão submetidos, em época de vestibular, as cobranças pessoais, familiares e sociais para um bom desempenho nos estudos. Estas pressões podem gerar um estado de ansiedade prejudicial ao desempenho acadêmico. Alguns sentimentos como o de solidão, insegurança e dúvidas (característicos da adolescência e que acompanham os vestibulandos durante quase todo o período pré-vestibular) podem resultar em pânico, sentimentos de incompetência e incapacidade. O drama psicológico vivido vai aumentando à medida que o exame se aproxima. $\mathrm{O}$ vestibulando pode vir a sofrer distúrbios psicofisiológicos levando até mesmo a depressão (Soares, 2002).

Segundo Oliveira e Duarte (2004), a tensão, incerteza e apreensão em relação ao futuro são componentes importantes da ansiedade que podem interferir na aprendizagem e no desempenho em geral. O sistema de classificação por notas leva o aluno à competição para a realização pessoal no desejo de ser aceito e valorizado pela família e pela sociedade. O fracasso pode levar a formação da crença que só os competentes bem sucedidos são amados e a possibilidade de fracassar e não ser amado por conseqüência pode ser vivida com sofrimento, tensão e ansiedade.

Soma-se a isto que é na adolescência que o cérebro da infância se transforma em um cérebro de adulto. Enquanto algumas estruturas crescem de fato, outras encolhem, sofrem reorganizações químicas e estruturais e todas acabam por amadurecer funcionalmente. No cérebro as regiões pré-frontais permitem o raciocínio abstrato e o aprendizado social. Com o adolescer há o amadurecimento, e com isso nasce o jovem adulto responsável - porque é capaz de antecipar as conseqüências de suas ações e assumi-las e empático porque consegue inferir e prever emoções dos outros e agir conforme suas previsões (Houzel, 2005). Entretanto, tantas mudanças também geram ansiedade, podendo alguns indivíduos apresentar maior dificuldade para suplantar tal fase.

Segundo Coelho (2002), os conflitos e as dificuldades dos adolescentes envolvem emoções significativas, e são múltiplas as situações que se caracterizam por um forte cunho emocional entre os adolescentes, já que nesta fase são pressionados a enfrentar e a resolver problemas, com os quais não estavam antes acostumados.

Com a entrada na adolescência o indivíduo é desafiado a enfrentar diversas ocorrências geradoras de angústia, uma delas é a escolha vocacional e a preparação para o mundo das profissões, buscando a significância e a finalidade para a vida, a descoberta de seu lugar no mundo estabelecendo novas relações fora da conjuntura familiar. A escolha profissional geralmente trás consigo dúvidas, questionamentos, ansiedade e, dependendo do desenrolar destes problemas, podem trazer emoções agradáveis ou grandes frustrações (Bianchetti, 1996).

Por ser vital ao homem e inerente à condição humana, a ansiedade não é um fenômeno patológico, desde que funcione para motivar e despertar o organismo, sendo necessário para colocá-lo em sobreaviso quando aparece algo ameaçador para a estabilidade emocional (Andrade \& Gorestein, 1998). Avaliando uma situação como ameaçadora, o indivíduo experimentará uma súbita elevação do estado de ansiedade. A duração e a intensidade deste estado vão depender do grau de ameaça que o indivíduo atribuirá à situação (Santarosa, 1984; Lipp, 2001).

Segundo Ladeira-Fernandes e Cruz (2007) a ansiedade é o resultado de uma atividade de um sistema saudável 
denominado medo. Este sistema é responsável pelo processamento de estímulos de perigo presentes no mundo externo. Certo grau de ansiedade é cogente para a sobrevivência humana, todavia se esta se apresentar de uma maneira constantemente exacerbada, o desempenho do indivíduo será prejudicado frente às várias situações que ele terá que enfrentar tais como provas, entrevistas, relacionamentos dentre outras (Biaggio, 1999, Lipp, 2003; Lipp, Arantes, Buriti, \& Witzig, 2003; Lipp \& Tanganelli, 2002).

Uma das maneiras de encaminhar as escolhas profissionais é prestar o exame vestibular. É real a concorrência acirrada para alcançar uma vaga na universidade. Segundo o último censo realizado pelo INEP/MEC-2003, existem $11,11 \%$ de vagas nas universidades públicas e nas universidades privadas $88.9 \%$, o que comprava a maior dificuldade de ingresso nas universidades públicas devido ao número reduzido de vagas (INEP, 2006).

Neste período advêm vários sentimentos, inclusive o temor de não corresponder às expectativas da família e da sociedade que interpretam a entrada na universidade como um certificado de competência e uma condição de "sucesso". Quando o estudante não consegue discernir o entrelaçamento desses fatores há uma invasão das angústias que distorcem a realidade, deixando funções psíquicas como razão e memória sob o domínio de emoções. Sintomas físicos indesejados também podem ser experimentados.

Diante do exposto, este trabalho objetivou comparar a ansiedade de adolescentes do $1^{\circ}$ e $3^{\circ}$ ano do ensino médio de escolas privadas que estão em fase de realização do vestibular seriado PISM.

\section{Método}

\section{Participantes}

Participaram voluntariamente 124 estudantes sendo 66 moças e 58 rapazes, 69 alunos eram do $1^{\circ}$ ano do Ensino Médio e 55 do $3^{\circ}$ ano. A média de idade dos estudantes pesquisados foi de 15,7 anos ( $\mathrm{DP}=1,2$ e $n=124)$, sendo que a média de idade entre os estudantes do $1^{\circ}$ ano foi de 14,8 anos $(\mathrm{DP}=0,6$ e $n=69)$ e entre os do $3^{\circ}$ ano foi de 16,8 anos (DP= $0,6$ e $n=55)$. Da amostra, $53,2 \%$ eram do sexo feminino e $55,6 \%$ pertenciam ao $1^{\circ}$ ano do ensino médio. Quanto à distribuição de gênero por série observou-se que, da população feminina, $54,5 \%$ eram estudantes da $1^{\circ}$ ano e $45,5 \%$ do $3^{\circ}$ ano, e entre os rapazes $56,9 \%$ do $1^{\circ}$ ano e $43,1 \%$ do $3^{\circ}$ ano. No total foram 69 alunos da $1^{\circ}$ ano e 55 do $3^{\circ}$ ano. No total foram 69 alunos do $1^{\circ}$ ano e 55 do $3^{\circ}$ ano. Todos os estudantes da amostra estavam inscritos no PISM.

\section{Instrumentos}

Para o registro dos dados sócio-demográficos foi pedido aos estudantes que se identificassem apenas pela inicial do nome, idade, escolaridade e gênero. Foi utilizado o Inventário de Ansiedade Traço-Estado - IDATE (Spielberg, Gorsuch, Lushene, Biaggio, \& Natalício, 1979) composto por duas escalas distintas de auto-relato, elaborados para medir dois conceitos distintos de ansiedade. A primeira parte foi elaborada para medir a ansiedade-estado e a segunda parte a ansiedade-traço. A escala de traço de ansiedade do IDATE consiste em 20 afirmações nas quais o indivíduo descreve como geralmente se sente. A escala de estado de ansiedade também consiste em 20 afirmações, mas as instruções requerem dos indivíduos indicarem como se sentem no determinado momento na qual estão respondendo a escala. É auto-aplicável e pode ser administrado individualmente ou em grupo. Não há limite de tempo para ser respondido.

Segundo Fioravante, Santos, Maissonette e Ladeira-Fernandeze (2006) o IDATE constitui-se um dos inventários mais utilizados de avaliação de ansiedade. Ainda segundo os mesmos autores o instrumento apresenta níveis elevados de consistência interna em ambas as escalas (estado Alpha de 0,89 e traço Alpha de 0,88 ): Os Alphas de Cronbach encontrados por Fioravante e cols. (2006) em ambas as escalas estão de acordo com aqueles previamente relatados na literatura com amostras brasileiras (Andrade, Gorenstein, Vieira, Tung, \& Artes, 2001; Pasquali, Pinelli Junior, \& Solha, 1994).

\section{Procedimento}

Para o desenvolvimento desta pesquisa foi solicitada a cinco escolas particulares de uma cidade do interior de $\mathrm{Mi}$ nas Gerais uma autorização por escrito para que os questionários pudessem ser aplicados. Quatro delas autorizaram a coleta de dados.

Os inventários foram aplicados pelos coordenadores pedagógicos das referidas escolas, previamente instruídos, durante o horário escolar. Foi esclarecido aos estudantes que sua participação era voluntária e que seria preservado o anonimato, bem como a confidencialidade dos dados. Foi assinado o Termo de Consentimento Livre e Esclarecido. Após o término da aplicação os questionários foram recolhidos imediatamente.

\section{Resultados e Discussão}

Para analisar a diferença de gênero foi utilizado o teste $t$ para diferenças de médias de amostras independentes. $\mathrm{O}$ teste foi precedido pelo Teste de Levene para igualdade de variâncias (Tabela 1)

Tabela 1

Diferenças de média na ansiedade-estado e ansiedade-traço por gênero

\begin{tabular}{cccccc}
\hline \multicolumn{5}{c}{ Estado } & M \\
Gênero & n & DP & t & p \\
\hline F & 66 & 44,27 & 8,62 & 2,12 & $0,036^{*}$ \\
M & 58 & 40,97 & 8,71 \\
\multicolumn{5}{c}{ Traço } \\
F & 66 & 45,42 & 9,11 & 4,10 & $0,000^{* *}$ \\
M & 58 & 39,09 & 7,93 & & \\
\hline
\end{tabular}

*Significativo $p<0,05$

** Significativo $p<0,001$ 
Observou-se uma diferença significativa de gênero quanto ao nível de ansiedade Traço-Estado. Indivíduos do sexo feminino revelaram estar mais sujeitos à ansiedade do que os do sexo masculino, corroborando os resultados de diversas pesquisas em torno deste tema (Silva, 1992; Pinto, 1996; Perez, Nicolau, Romano, \& Lanranjeira, 2005).

Kessler e cols. (1994) afirmam que, conforme pesquisas epidemiológicas da população geral dos EUA, as moças têm probabilidade significativamente maior do que os rapazes de desenvolver transtornos de ansiedade. Segundo Kinrys e Wugant (2005), as evidências na literatura mostram que, além de ocorrer uma maior prevalência de transtornos de ansiedade nas moças, as diferenças de gêneros também existem na apresentação clínica e nas características de tais transtornos.

Utilizou-se o teste $t$ de Student para avaliar a variável ano de escolaridade (Tabela 2). Não foram encontradas diferenças significativas de ansiedade entre os alunos do $1^{\circ}$ e do $3^{\circ}$ ano, nem no que diz respeito à ansiedade-traço $(p=0,96)$ nem para ansiedade-estado $(p=0,64)$. Os alunos do $1^{\circ}$ ano, que estão prestando o vestibular PISM, são tão ansiosos quanto os alunos do $3^{\circ}$ ano que também estão em fase de avaliação.

Tabela 2

Variável ano de escolaridade e ansiedade-estado e ansiedade-traço

\begin{tabular}{cccccc}
\hline \multicolumn{6}{c}{ Estado } \\
Série & $\mathbf{N}$ & $\mathbf{M}$ & $\mathbf{D P}$ & $\mathbf{t}$ & $\mathbf{p}$ \\
\hline $1^{\text {o }}$ & 69 & 43,06 & 8,33 & 0,47 & 0,64 \\
$3^{\text {o }}$ & 55 & 42,31 & 9,38 \\
\multicolumn{5}{c}{ Traço } \\
$1^{\text {o }}$ & 69 & 42,42 & 8,43 & $-0,05$ & 0,96 \\
$3^{\text {o }}$ & 55 & 42,51 & 9,98 & & \\
\hline
\end{tabular}

A adolescência é um período longo e a complexidade das tarefas com que os jovens vão ser confrontados são cada vez maiores. Eles nem sempre estão preparados para lidar com as exigências das novas situações. Em pesquisa realizada com 960 indivíduos sobre o bem-estar psicológico nos adolescentes, realizada por Silva, Horta, Pontes, Faria, Souza, Cruzeiro e Pinheiro (2007), foi constatado que existe uma tendência para o bem-estar diminuir com a idade. As trajetórias identificadas mostraram que os adolescentes mais novos (12 aos 13 anos e meio - início da adolescência) apresentam valores que apontam para um maior bem-estar. A partir desta idade estes valores se alteram, verificando-se uma diminuição do grupo dos 16 aos 17 anos e meio (final da adolescência). Por meio dos resultados pode-se identificar um período de idade no qual os jovens poderão ser considerados com maior vulnerabilidade para mudanças em relação ao bem-estar psicológico e, consequentemente, de maior risco.

O presente estudo veio reforçar a preocupação frente à atual amostra que se insere na faixa etária de risco apresentada acima. A ansiedade encontra-se no mesmo nível tanto para alunos do $1^{\circ}$ ano (e são os mais novos da amostra) como para os alunos do $3^{\circ}$ ano (que são os mais velhos). Com isso, os alunos do $1^{\circ}$ ano, que apresentam idade cronológica inferior, apresentam uma maior dificuldade em lidar com as exigências cotidianas do que os alunos do $3^{\circ}$ ano. Estes dados apóiam a idéia de que alunos do $1^{\circ}$ ano que estão fazendo o Vestibular Seriado apresentam sintomas de ansiedade excessiva em uma idade ainda precoce.

Com relação à ansiedade em moças e rapazes entre séries, foi encontrada diferença significativa com relação à ansiedadeestado (Tabela 3). Observa-se que moças do $1^{\circ}$ ano são mais ansiosas do que rapazes do $1^{\circ}$ ano $(\mathrm{p}=0,004)$. $\mathrm{O}$ mesmo dado se repetiu com relação à ansiedade-traço: as moças do $1^{\circ}$ ano são mais ansiosas do que rapazes do $1^{\circ}$ ano $(\mathrm{p}=0,000)$.

Tabela 3

Análise da ansiedade-estado e ansiedade-traço em homens e mulheres dentro de cada série

\begin{tabular}{ccccccc}
\hline Série & Sexo & N & $\begin{array}{c}\text { Estado } \\
\mathbf{M}\end{array}$ & DP & t & p \\
\hline $1^{\text {o }}$ & Feminino & 36 & 45,75 & 7,62 & 2,96 & $0,004^{*}$ \\
$1^{\text {o }}$ & Masculino & 33 & 40,12 & 8,18 & & \\
$3^{\text {o }}$ & Feminino & 30 & 42,50 & 9,51 & 0,16 & 0,87 \\
$3^{\text {o }}$ & Masculino & 25 & 42,08 & 9,41 & & \\
& & \multicolumn{7}{c}{ Traço } & & & \\
$1^{\text {o }}$ & Feminino & 36 & 45,97 & 8,09 & 4,05 & $0,000^{* *}$ \\
$1^{\text {o }}$ & Masculino & 33 & 38,55 & 7,06 & & \\
$3^{\text {o }}$ & Feminino & 30 & 44,77 & 10,30 & 1,88 & 0,06 \\
$3^{\text {o }}$ & Masculino & 25 & 39,80 & 9,05 & & \\
\hline
\end{tabular}

*Significativo $\mathrm{p}<0,05$

*Significativo $\mathrm{p}<0,001$

Estes resultados confirmam que moças são mais ansiosas do que os rapazes e que o fato de estarem ainda a longo caminho do resultado final do exame vestibular possivelmente as deixa bastante ansiosas. Segundo Manso e Matos (2006) o estudo das diferenças de gênero registra que as moças diferenciaram-se dos rapazes no que diz respeito à depressão e à ansiedade. As moças relatam níveis gerais mais elevados de depressão e de ansiedade em comparação aos rapazes, o que é consistente com vários estudos realizados acerca das diferenças de gênero na saúde mental, especialmente no que tange à depressão e ansiedade (Matos, Barrett, Dadds, \& Shortt, 2003). Estas diferenças do gênero parecem emergir no início da adolescência e mantêm-se ao longo da vida adulta (Kessler e cols., 1994). Ainda segundo Manso e Matos (2006) adolescentes que vivem em meio urbano relataram mais sintomas gerais de depressão e ansiedade.

Em relação às moças e rapazes do $3^{\circ}$ ano, para a ansiedade-traço não foram encontradas diferenças significativas. Não foi encontrada também diferença na ansiedade-estado entre rapazes e moças do $3^{\circ}$ ano $(p=0,87)$. Pode-se supor que tal fato ocorra pelo nível de ansiedade destes estudantes que, por estarem mais próximos ao vestibular, se sentem 
muito ansiosos a ponto de igualarem à ansiedade-estado das mulheres, que têm se mostrado mais ansiosas (Hollander \& Simeon, 2004).

\section{Considerações finais}

Esse trabalho procurou comparar os níveis de ansiedade traço e estado em estudantes do primeiro e terceiro anos do ensino médio inscritos no vestibular seriado PISM. Segundo pesquisas realizadas por Calais, Andrade e Lipp (2003), o estresse encontrado nos estudantes é maior durante o período de preparo para o vestibular, deduzindo-se, assim, que este é um estressor de grande impacto para os jovens. Estudos realizados por Calais e cols. (2003) levantam a possibilidade também de que a habilidade em lidar com o estresse e a ansiedade talvez seja um elemento importante para o sucesso em um vestibular, tanto ou talvez até mais do que a habilidade acadêmica ou o conhecimento.

Constatou-se que existe diferença significativa de gênero quanto ao nível de ansiedade Traço-Estado. O sexo feminino revelou estar mais sujeito à ansiedade do que os indivíduos do sexo masculino, corroborando os resultados de diversas pesquisas em torno deste tema (Silva, 1992; Pinto, 1996; Perez e cols., 2005).

As considerações de Biaggio (1999) acerca da exasperação da ansiedade em geral, nas pessoas cujo Traço é alto, explica o resultado obtido nesta pesquisa em que se verificou um alto índice de ansiedade-traço e conseqüentemente, de ansiedade-estado, nos participantes do sexo feminino e a correlação positiva em que quanto maior o Traço de ansiedade maior o Estado.

Em seguida apurou-se, analisando o ano de escolaridade e ansiedade Traço-Estado, não existirem diferenças significativas entre séries. Possivelmente os alunos do $1^{\circ}$ ano, que estão prestando o vestibular PISM, são tão ansiosos quanto os alunos do $3^{\circ}$ ano, que também estão em fase de avaliação. Este dado é preocupante, pois os alunos do $1^{\circ}$ ano são mais jovens e deveriam ser menos ansiosos do que os alunos do $3^{\circ}$ ano, que estão em fase final de vestibular.

Desse modo, deparando-se com os dados colhidos nesta pesquisa, faz-se importante estudar alternativas e estratégias de apoio a estes indivíduos, para que frente a uma situação de estresse o nível de ansiedade apresentado não seja prejudicial em sua vida.

A ansiedade afeta cada indivíduo de forma diferenciada por estar relacionada a diversos fatores biofisiológicos, sociais e psicológicos. Moças e rapazes não só diferem em características biológicas, mas também na variedade de papéis que desempenham socialmente. A interação entre os papéis sociais e os eventos vitais negativos podem produzir resultados diferentes na resposta.

Segundo Hoffman (1998, citado em Calais e cols., 2003), além das diferenças de sexo, deve-se levar em conta que a idade possibilita reações diferentes aos eventos estressores da vida. Calais e cols. (2003), em uma pesquisa sobre escolaridade e estresse, descobriram que as mulheres eram mais afetadas pelo estresse do que os rapazes em todas as faixas etárias pesquisadas. No entanto, os fatores que podem levar a essa diferença permanecem indeterminados.

Existem recursos para diminuir a ansiedade. Biaggio (1999) recomenda que se utilize o recurso da identificação ou da imitação. Do mesmo modo como um modelo pode servir para deixar o outro ansioso, espelhar-se em pessoas que não apresentam ansiedade em determinadas situações pode ser um excelente recurso. A técnica da reestruturação cognitiva, que visa substituir crenças irracionais ou pensamentos catastróficos por outros mais funcionais, também é muito utilizada.

\section{Referências}

Andrade, L., \& Gorestein R. (1998). Aspectos gerais das escalas de avaliação de ansiedade. Revista de Psiquiatria Clínica, 25, 285-290.

Andrade, L., Gorenstein, C., Vieira, A. H., Tung, T. C., \& Artes, R. (2001). Psychometric properties of the Portuguese version of the State-Trait Anxiety Inventory applied to college students: Factor analysis and relation to the Beck depression Inventory. Brazilian Journal of Medical and Biological Research, 34, 367-374.

Biaggio, A. M. B (1999). A ansiedade do dia-a-dia. In M. N. Lipp (Org.), O stress está dentro de você. São Paulo: Contexto.

Bianchetti, L. (1996). Angústia no vestibular: Indicações para pais e professores. Passo Fundo: EDIUPUF.

Calais, S. L., Andrade, L. M. B., \& Lipp, M. E. N. (2003). Diferenças de sexo e escolaridade na manifestação do stress em adultos jovens. Psicologia: Reflexão \& Crítica, 16, 257-263.

Coelho, A. R. M. (2002). Valores em adolescentes. Dissertação de Mestrado não-publicada, Universidade Gama Filho, Rio de Janeiro.

D’Avila, G. T., \& Soares, D. H. P. (2003) Vestibular: Fatores geradores de ansiedade na cena da prova. Revista Brasileira de Orientação Profissional, 4(1-2), 105-116.

Fioravanti, A. C. M., Santos, L. F., Maissonette, S., Cruz, A. P. M., \& Ladeira-Fernandez, J. (2006). Avaliação da estrutura fatorial da Escala de Ansiedade-Traço do IDATE. Avaliação Psicológica, 5, 217-224.

Hollander, E., \& Simeon, D. (2004). Transtorno de ansiedade (M. F. Lopes, Trad.). Porto Alegre: Artmed.

Houzel, S. H. (2005). O cérebro em transformação. Rio de Janeiro: Objetiva.

Instituto Nacional de Estudos e Pesquisas Anísio Teixeira. (2006). Recuperado em 10 de março de 2009, de http:// www.inep.gov.br/superior/censosuperior/default.asp

Kessler, R. C., McGonagle, K. A., Zhao, S., Nelson, C. B., Hughes, M., Eshleman, S., Wittchen, H-U., \& Kendler, K. S. (1994). Lifetime and 12-month prevalence of DSM-III-R psychiatric disorders in the United States: Results from the National Comorbidity Survey. Archives of General Psychiatry, 51, 8-19. 
Kinrys, G., \& Wygant, L. E. (2005). Transtornos de ansiedade em mulheres: Gênero influencia o tratamento? Revista Brasileira de Psiquiatria, 27, 43-50.

Landeira-Fernandez, J., \& Cruz, A. P. M. (2007). Medo e dor e a origem da ansiedade e do pânico. In J. LandeiraFernandez \& M. T. A. Silva (Orgs.), Intersecções entre Neurociência e Psicologia (pp. 217-239). Rio de Janeiro: MedBook.

Lipp, M. E. N. (2001). Estresse emocional: A contribuição de estressores internos e externos. Revista de Psiquiatria Clínica, 28, 347-348.

Lipp, M. E. N. (Org). (2003). Mecanismos neuropsicofisiológicos do stress: Teoria e aplicações clínicas. São Paulo: Casa do Psicólogo.

Lipp, M. E. N., Arantes, J. P., Buriti, M. S., \& Witzig, T. (2003). Stress em escolares. Revista Acta Cientifica: Ciências Humanas, 1(4), 16, 51-56.

Lipp, M. E. N., \& Tanganelli, M. S. (2002). Stress e qualidade de vida em magistrados da justiça do trabalho: Diferenças entre homens e mulheres. Psicologia. Reflexão e Crítica, 15, 537-548.

Levenfus, R. S. (1993). Vestibular: Derrubando o mito. Porto Alegre: Gente.

Manso, D. S. S., \& Matos, M. G. (2006). Depressão, ansiedade e consumo de substâncias em adolescentes. Revista Brasileira de Terapias Cognitivas, 2(1), 73-84.

Matos, M. G., Barrett, P., Dadds, M., \& Shortt, A. (2003). Anxiety, depression, and peer relationships during adolescence: Results from the portuguese national health behaviour in school-aged children survey. European Journal of Psychology of Education, 1, 3-14.

Oliveira, M. A., \& Duarte, A. M. M. (2004). Controle de respostas de ansiedade em universitários em situações de exposições orais. Revista Brasileira de Terapia Comportamental e Cognitiva, 6, 183-200.

Pasquali, L., Pinelli Junior, B., \& Solha, A. C. (1994). Contribuição à validade e normatização da escala de ansiedade traço-estado do IDATE. Psicologia: Teoria e Pesquisa, 10, 411-420.

Perez, G. H., Nicolau, J. C, Romano, B. W., \& Lanranjeira, R. (2005). Depressão e síndromes isquêmicas miocárdicas instáveis: Diferenças entre homens e mulheres. Arquivos Brasileiros de Cardiologia, 85(5), 319-326.

Pinto, W. (1996). Stress, qualidade de vida e vitiligo. In M. N. Lipp (Org.), Pesquisas sobre stress no Brasil: Saúde, ocupações e grupos de risco (pp.129-148). Campinas: Papirus.

Santarosa, L. (1984). Computador, avaliação e ansiedade. Arquivos Brasileiros de Psicologia, 36(3), 38-52.

Silva, A. C. A. (1992). Estresse em bancários: Qualidade de vida, estresse e estressores presentes em uma amostra de funcionários do Banco do Brasil. Dissertação de Mestrado não-publicada, Pontifícia Universidade
Católica, Campinas.

Silva, R. A., Horta, B. L., Pontes, L.M., Faria, A. D., Souza, L. D., Cruzeiro, A. L. S. \& Pinheiro, R. T. (2007). Bemestar psicológico e adolescência: fatores associados. Cadernos de Saúde Pública, 23, 1113-1118.

Spielberg, C. D., Gorsuch, R., L., Lushene, R., E. Biaggio, A. M. B., \& Natalício, L. (1979). Inventário de Ansiedade Traço-Estado - IDATE. Rio de Janeiro: Cepa.

Soares, D. H. P. (2002). Como trabalhar a ansiedade e o estresse frente ao vestibular. In R. S. Levenfus \& D. H. P. Soares (Orgs.), Orientação vocacional ocupacional: Novos achados teóricos, técnicos e instrumentos para a clínica, a escola e a empresa. Porto Alegre, RS: Artmed.

Adriana Benevides Soares é professora Titular da Universidade Salgado de Oliveira, campus Niterói e Professora Adjunta do Departamento de Fundamentos da Psicologia, da Universidade do Estado do Rio de Janeiro, campus Maracanã.

Janaína Siqueira Rodrigues Martins é mestre em Psicologia pelo Programa de Pós-Graduação em Psicologia da Universidade Gama Filho.
Recebido: $17 / 10 / 2008$

$1^{a}$ revisão: $15 / 06 / 2009$

$2^{a}$ revisão: 06/07/2009

Aceite final: 22/07/2009 